\title{
Quality of Life of Drug Reaction with Eosinophilia and Systemic Symptom (DRESS) and Stevens-Johnson Syndrome (SJS) and/or Toxic Epidermal Necrolysis (TEN) Patients
}

This article was published in the following Dove Press journal:

Patient Preference and Adherence

\section{Dyah Aryani Perwitasari (iD) \\ Sri Awalia Febriana ${ }^{2}$ \\ Ratna Septi Tristiana' \\ 'Faculty of Pharmacy, Universitas Ahmad Dahlan, Yogyakarta, Indonesia; \\ ${ }^{2}$ Department of Dermatology and \\ Venereology, Universitas Gadjah Mada, \\ Yogyakarta, Indonesia}

Purpose: Drug Reaction With Eosinophilia and Systemic Symptom (DRESS), StevensJohnson Syndrome (SJS), and Toxic Epidermal Necrolysis (TEN) are acute hypersensitivity reactions with the potential to reduce the quality of life of exposed individuals. This study aims to determine the quality of life of patients suffering from DRESS, SJS, SJS/TEN.

Patients and Methods: A cross-sectional approach was used to get the quality of life data from DRESS, SJS, and/or TEN patients at Dr. Sardjito general hospital, Yogyakarta. The utility index and VAS score differences of EQ-5D-5L were analyzed based on the diagnosis. Results: We recruited 58 patients. Most of the patients were female (63\%). The mean value of utility index was $0.61,0.08$ and 0.03 for DRESS, SJS and SJS/TEN patients, respectively ( $p$ value $<0.01$ ). Furthermore, the mean of VAS score was 73.36, 57.93 and 50.00 for DRESS, SJS and SJS/TEN patients, respectively ( $p$ value $<0.01$ ).

Conclusion: In general, the quality of life of DRESS patients is better than the quality of life of SJS and/or TEN patients.

Keywords: DRESS, QoL, SJS, TEN, skin diseases

\section{Introduction}

Pharmaceutical services are essential health practices that aim to increase rational drug use, the safety, cost efficiency, and the quality of life of patients. ${ }^{1}$ According to previous research, problems related to drug quality and therapy failure cause greater costs for patients. $^{2}$ Advances in health science, especially pharmacy, have a great impact on drug use, which directly causes some side effects (adverse drug reaction). The drug side effects that occur on the skin are called adverse cutaneous drug reaction (ACDR), ${ }^{3}$ while at an intense level, they are called severe cutaneous adverse reaction (SCAR). ${ }^{4}$

The SCAR incidence, such as drug reaction with eosinophilia and systemic symptom (DRESS), Stevens-Johnson syndrome (SJS), and toxic epidermal necrolysis (TEN) rarely occurred, however, they have the potential to cause disabilities or death with $10 \%$ mortality rate. ${ }^{5,6}$ The DRESS is a collection of symptoms and idiosyncratic allergic reactions caused by drug administration in therapeutic doses. ${ }^{7}$ At the advanced stages of DRESS, several organ dysfunctions arise in the liver, kidneys, lungs, and heart. ${ }^{3,8}$ The most common complications in DRESS patients are found in the liver (50-87\%) and kidneys (10-53\%). ${ }^{9}$
Correspondence: Dyah Aryani Perwitasari Faculty of Pharmacy, Universitas Ahmad Dahlan, Kampus 3 UAD, JI Prof Dr Soepomo, Janturan, Yogyakarta, 55I64, Indonesia

$\mathrm{Tel} / \mathrm{Fax}+62274563515$

Email dyah.perwitasari@pharm.uad.ac.id
Patient Preference and Adherence 2021:15 329-335 
The SJS and TEN are severe and life-threatening diseases involving the skin and mucous membranes, characterized by the release of epidermis, water-filled lesions, and peeling of the mucosa. They also occur due to reactions from drugs, although the occurrence is rare. ${ }^{10}$ The difference between SJS and TEN is the percentage of affected body surface, SJS affects $10 \%$, while TEN attacks $30 \%$, and the occurrence of both SJS-TEN cause skin lesions of $10 \%-$ $30 \%$. The incidences of SJS and TEN are 1-6 cases and $0.4-1.2$ cases/million/year, respectively. ${ }^{11}$

DRESS, SJS and TEN are not only health problems, they also cause psychological stress and fear following the life-threatening reactions. Most DRESS, SJS, and TEN patients are found to receive outpatient care after being hospitalized by primary doctors, such as internal medicine specialists, skin and genital specialists. The research conducted in Korea stated that SJS and TEN treatment costs are comparable to treating the five most expensive diseases nationally. ${ }^{12,13}$ Meanwhile, in the DRESS case, some patients experienced relapse a few months after the first hospitalization, this caused additional costs. ${ }^{14}$

The research conducted by Nogueira (2003) stated that the assessment of SJS/TEN patients' quality of life using the Short Formulary-36 (SF-36) questionnaire shows some problems, such as psychological, social, and economic disorders for approximately 30 years. All these occur at productive age, causing high anxiety and depression. ${ }^{15}$ In this study, the Euro Quality of Life-5 Dimensions (EQ-5D) questionnaire was used due to its easy and understandable features. The high mortality rate of these illnesses, the cost impact, and the patients' quality of life are important information for pharmacists, doctors, and policy makers during treatment periods. Therefore, this research was carried out based these attributes at Dr. Sardjito general hospital, Yogyakarta from 2014 to 2018. The purpose of this study was to determine the quality of life of DRESS, SJS, and TEN patients.

\section{Patients and Methods}

This study was an observational, with cross-sectional approach, which was conducted prospectively. A total of 21 DRESS, 32 SJS, 5 SJS/TEN hospitalized patients were included in this study, with the code ICD-10 DRESS (L.27.0), SJS (L51.1), and TEN (L51.2). The ICD-10 code has been implemented since 2006. The diagnosis of DRESS, SJS/TEN and causality analysis was defined by the physician. We collected the patients' characteristics and drugs used from the patients' medical record, from
January to December 2019 and we did not use the sample size due to the limited number of patients.

Patients' quality of life data was collected using EQ5D-5L questionnaire. The patients gave their consents prior to the commencement of this study and they filled in the questionnaire during the hospital discharge. The patients were also informed about the purpose of the study. This study was approved by the Medical and Health Research Ethics Committee, Faculty of Medicine, Gadjah Mada University-Dr. Sardjito Yogyakarta, with ethical approval number KE/FK/1111/ EC 19 October 2018 and conducted in accordance with the Declaration of Helsinki.

To define the patients' quality of life, the EQ-5D-5L (five level) questionnaire was used. The EQ-5D-5L instrument is a standardized system that collects quality of life information on five dimensions: mobility, self-care, daily activities, pain/discomfort, anxiety/depression. Each domain is scored from 1 to 5 , with 1 having no problems, 2 slight problems, 3 moderate, 4 severe, and 5 being unable to undertake the activity described. This questionnaire is already available and validated in Bahasa Indonesia. ${ }^{16}$ The five dimensions digit can be combined into a 5-digit number that describes the participant's quality of life. For example, state 11,111 indicates no problems on any of the 5 dimensions, while state 12,345 indicates no problems with mobility, slight problem with self-care, moderate problems with doing daily activities, severe pain or discomfort, and extreme anxiety or depression. ${ }^{16}$

To convert an individual EQ-5D-5L health state to a single EQ-5D-5L index score, standard values (weights) which are attributed to each of the levels in each dimension, are obtained from the Indonesian value set. The index is calculated by deducting from 1 the appropriate weights for the value for full health (i.e.state 12,345). The EQ-5D-5L instrument also describes self-reported overall health status on a visual analogue scale (EQ-VAS), which has a score between 0 ("worst imaginable health status") and 100 ("best imaginable health state"). Both the EQ-5D$5 \mathrm{~L}$ utility index and VAS score are used as dependent variables in the statistical analysis. ${ }^{16}$

A comparison was made by assessing the utility index and VAS score of DRESS, SJS, and TEN patients using One-Way Anova test.

\section{Results}

We recruited 21.32 and 5 patients of DRESS, SJS and SJS/ TEN, respectively. The patients demographic data and 
Table I Clinical and Demographic Characteristics of DRESS, SJS, and SJS/TEN Patients

\begin{tabular}{|c|c|c|c|}
\hline Characteristics & DRESS (\%) N = 21 & SJS (\%) $N=32$ & SJS/TEN (\%) $N=5$ \\
\hline \multicolumn{4}{|l|}{ Gender } \\
\hline Male & $8(38)$ & $17(53)$ & $2(40)$ \\
\hline Female & $13(62)$ & $21(65)$ & $3(60)$ \\
\hline Age (Mean $\pm S D)$ & $38,8 \pm 10.97$ & $33,3 \pm 17,20$ & $34 \pm 13$ \\
\hline IQR, $p$ value: 0.521 & 16.00 & 27.00 & 28.50 \\
\hline Hospitalization duration & $10,5 \pm 6.70$ & $11,6 \pm 5.60$ & $12 \pm 2.90$ \\
\hline IQR, $p$ value: 0.749 & 13.50 & 12.75 & 5.50 \\
\hline \multicolumn{4}{|c|}{ Causative Agent (ATC Classification) } \\
\hline Antibiotic (J0ICA04) & $14(67)$ & $18(56)$ & $4(80)$ \\
\hline NSAIDs (MOIA) & $5(24)$ & $6(18)$ & I (20) \\
\hline OAT (J04A) & $3(14)$ & $2(6)$ & $0(0)$ \\
\hline ARV (J05A) & I (5) & $4(12.5)$ & I (20) \\
\hline Anti-convulsant (N03AA) & $3(14)$ & $14(44)$ & I (20) \\
\hline Other & $0(0)$ & $16(50)$ & $3(60)$ \\
\hline
\end{tabular}

Abbreviations: NSAIDs, non-steroidal anti-inflammatory drugs; OAT, anti-tuberculosis drug; ARVs, antivirals; other drugs, such as allopurinol, paracetamol, domperidone, ambroxol, tramadol, diazepam, and bromhexine.

clinical characteristics such as gender, age, duration of hospitalization, causative agent, and therapy during the treatment is shown in Table 1. The frequency of DRESS (62\%), SJS (65\%), and SJS/TEN (60\%) in female are greater compared to male patients, with the highest mean age is 38.8 years old. The mean hospitalization duration for DRESS, SJS and SJS/TEN patients are 10.5, 11.6 and 12 days, respectively.

The main drugs causing DRESS are antibiotics (67\%) followed by non-steroidal anti-inflammation drugs (NSAIDs) (24\%), oral anti-tuberculosis (14\%), and anticonvulsants $(14 \%)$. Meanwhile, the main cause of SJS is antibiotics (56\%), followed by anti-convulsants (44\%), and NSAIDs (18\%), while TEN was antibiotics (80\%), followed by NSAIDs (20\%), anti-retrovirals (ARVs) $(20 \%)$, and anti-convulsants (14\%).

An overview of the patient's treatment is shown in Table 2. All the DRESS, SJS, and TEN patients received fluid and electrolyte therapy (100\%). The specific therapy given to DRESS patients is corticosteroid injection (90\%), while for those with SJS are corticosteroid injection (96\%), oral corticosteroids (90\%), and cyclosporin-corticosteroid (3\%). Lastly, for TEN patient there are corticosteroids injection $(100 \%)$ and oral corticosteroids (60\%).

Table 3 presents the utility and VAS differences between DRESS, SJS and SJS/TEN patients. The utility value of DRESS patients is higher than the utility value of SJS and SJS/TEN patients ( 0.62 vs 0.08 and 0.03 ). The VAS score of DRESS patients is also higher than the VAS score of SJS and SJS/TEN patients (73.36 vs 57.93 and 50.00). The differences of utility and VAS score among the groups are significant ( $\mathrm{p}$ value $<0.05$ ). However, there are no significant differences of utility index and VAS scores between SJS and SJS/TEN groups.

Table 4 presents the health profiles of DRESS, SJS and SJS/TEN patients based on EQ-5D-5L. In the mobility, self-care, usual activities and anxiety/depression, the proportion of DRESS patients with "no problem" and "severe problem" is higher than SJS and SJS/TEN patients. However, in the pain/discomfort dimension, patients in all diagnosis, experience more severe problems. In general, The DRESS patients have better health profiles in all dimensions than other diagnosis. This situation is also presented by Table 5, whereas only DRESS and SJS patients state the best health, based on the VAS score. Furthermore, the proportion of patients with the best health is higher in DRESS diagnosis than SJS. Patients with SJS and SJS/TEN have the worst health.

\section{Discussion}

Our study shows that in general, DRESS patients had better quality of life than SJS/TEN patients. The female patients have a higher incidence of DRESS, SJS, and SJS/ TEN compared to men. This result is in accordance with that of Velasco-Tirado et al (2018), which stated that SJS/ TEN were more common in women than men, with a male to female ratio of $0.6 .{ }^{17}$ The mean age of DRESS, SJS, and TEN patients in this study is not significantly different. 
Table 2 Overview of Inpatient Treatment of DRESS, SJS, and SJS/TEN

\begin{tabular}{|c|c|c|c|}
\hline \multirow[t]{2}{*}{ Drug Therapy } & \multicolumn{3}{|c|}{ The Number of Patient (\%) } \\
\hline & DRESS (N = 2I) & SJS $(\mathbf{N}=32)$ & SJS/TEN $(N=5)$ \\
\hline \multicolumn{4}{|l|}{ Supportive Therapy (ATC Classification) } \\
\hline Acid-related disorder drugs (A02) & & $20(63)$ & $5(100)$ \\
\hline Antihistamines (R06) & & $22(69)$ & $4(80)$ \\
\hline Analgesic (N02) & & $21(66)$ & $4(80)$ \\
\hline Fluid and electrolyte therapy (B05XA) & & $32(100)$ & $5(100)$ \\
\hline Antithrombotic agents (BOI) & $21(100)$ & $5(16)$ & $2(7)$ \\
\hline Antibiotic (J0ICA04) & & $16(50)$ & $5(100)$ \\
\hline \multicolumn{4}{|l|}{ Specific Therapy } \\
\hline Corticosteroid injection $(\mathrm{H} 02)$ & $19(90)$ & $31(96)$ & $5(100)$ \\
\hline Corticosteroid oral $(\mathrm{H} 02))$ & $19(90)$ & $29(90)$ & $3(60)$ \\
\hline Cyclosporine + corticosteroid $(\mathrm{L} 40 \mathrm{DOI}+\mathrm{H} 02)$ & & I (3) & $0(0)$ \\
\hline \multicolumn{4}{|l|}{ Topical Therapy } \\
\hline Eye medications (corticosteroids D07) & $5(24)$ & $8(25)$ & $0(0)$ \\
\hline Eye medications (Antibiotics D06A) & & $20(63)$ & $3(60)$ \\
\hline Eye medications (Eomlien and protectives D03A) & $14(67)$ & $25(78)$ & $4(80)$ \\
\hline Skin medications (corticosteroids D07) & & $3(9)$ & I (20) \\
\hline Skin medications (antibiotics D06A) & & $26(81)$ & $4(80)$ \\
\hline Skin medications (emollients D02A) & & $15(47)$ & $3(60)$ \\
\hline Skin medications (antiseptic/silver sulfadiazine D08AL) & & $20(63)$ & $3(60)$ \\
\hline Mouthwash (antiseptic D08AG) & & $8(25)$ & $1(20)$ \\
\hline
\end{tabular}

Meanwhile, other studies had reported that the incidence rate and age increase were equal. Therefore, the higher the age, the greater the risk of experiencing skin disorders, such as SJS and TEN, due to high rate of drug consumption at older age and their interactions. ${ }^{18,19}$

The mean of hospitalization duration for DRESS, SJS, and TEN patients were less than the mean of hospitalization of study conducted by Yang et $a{ }^{13}{ }^{13}$ in Korea. The study showed that hospitalization duration of SJS patients had no significant difference from those with TEN. The average hospitalization duration for SJS and TEN patients

Table 3 The Mean Score of Utility and VAS in DRESS, SJS and SJS/TEN Patients

\begin{tabular}{|l|l|l|l|l|}
\hline Patients & $\mathbf{n}$ & Utility Mean, IQR & SD & p value \\
\hline DRESS & 21 & $0.61,0.44$ & 0.23 & $0.00 I^{*}$ \\
SJS & 32 & $0.08,0.65$ & 0.42 & \\
SJS/TEN & 5 & $0.03,1.08$ & 0.01 & \\
\hline & & VAS Mean, IQR & SD & p value \\
\hline DRESS & 21 & $73.36,26.25$ & 14.48 & $0.008^{*}$ \\
SJS & 32 & $57.93,32.50$ & 26.37 & \\
SJS/TEN & 5 & $50.00,55.00$ & 24.35 & \\
\hline
\end{tabular}

Note: *Significant difference (normally distributed data), One way Anova test. were 20 (8-60 days) and 21.5 (20-292 days), respectively. Meanwhile, the duration for DRESS patients were shorter than that of SJS and TEN, which was 14 (3-218) days. ${ }^{13}$

The drug class that most often caused DRESS, SJS, and SJS/TEN in this study is antibiotics. Those causing DRESS are cefadroxil, ceftazidime, cefuroxime, cefixime, ceftriaxone, dapsone, cefotaxime, cotrimoxazole, and ciprofloxacin. These results are in accordance with previous studies which showed that, antibiotics caused the highest and most common cases of DRESS. ${ }^{20-22}$ The drugs that caused the greatest incidence of SJS and TEN are also antibiotics. This result is consistent with previous research, which stated that the largest drug class causing SJS/TEN was antibiotics (40\%), namely penicillin, cotrimoxazole, cephalosporins, quinolones, carbapenems, clindamycin, tetracyclines, and macrolides. ${ }^{23}$ The research conducted in India stated that the largest group of agents causing SJS/TEN were antibiotics $(35.55 \%)$, followed by anticonvulsants $(28.89 \%)$, and antipyretics (17.78\%). The reported antibiotics were fluoroquinolone (ofloxacin, norfloxacin, and levofloxacin), and sulfonamides (sulfametizol and sulfasalazine). ${ }^{24}$ Another previous study stated that sulfadoxine exposure is one of the risk factors of ocular and mucocutaneous sequelae in SJS/TEN survivors. ${ }^{25}$ 
Table 4 Health Profiles of DRESS, SJS and SJS/TEN Patients Based on EQ-5D-5L

\begin{tabular}{|c|c|c|c|c|}
\hline Dimensions & & $\begin{array}{l}\text { DRESS } \\
\text { (\%) }\end{array}$ & $\begin{array}{l}\text { SJS } \\
\text { (\%) }\end{array}$ & $\begin{array}{l}\text { SJSI } \\
\text { TEN (\%) }\end{array}$ \\
\hline Mobility & $\begin{array}{l}\text { No problem } \\
\text { Slight problem } \\
\text { Moderate problem } \\
\text { Severe problem } \\
\text { Unable to do }\end{array}$ & $\begin{array}{l}36.4 \\
31.8 \\
31.8 \\
0 \\
0\end{array}$ & $\begin{array}{l}10.3 \\
34.5 \\
31.0 \\
13.8 \\
10.3\end{array}$ & $\begin{array}{l}20.0 \\
40.0 \\
0 \\
20.0 \\
20.0\end{array}$ \\
\hline Self care & $\begin{array}{l}\text { No problem } \\
\text { Slight problem } \\
\text { Moderate problem } \\
\text { Severe problem } \\
\text { Unable to do }\end{array}$ & $\begin{array}{l}40.9 \\
27.3 \\
31.8 \\
0 \\
0\end{array}$ & \begin{tabular}{l|}
3.4 \\
44.8 \\
17.2 \\
17.2 \\
17.2
\end{tabular} & $\begin{array}{l}0 \\
0 \\
20.0 \\
40.0 \\
40.0\end{array}$ \\
\hline $\begin{array}{l}\text { Usual } \\
\text { activities }\end{array}$ & $\begin{array}{l}\text { No problem } \\
\text { Slight problem } \\
\text { Moderate problem } \\
\text { Severe problem } \\
\text { Unable to do }\end{array}$ & $\begin{array}{l}50.0 \\
31.8 \\
18.2 \\
0 \\
0\end{array}$ & $\begin{array}{l}0 \\
31.0 \\
34.5 \\
20.7 \\
13.8\end{array}$ & $\begin{array}{l}20.0 \\
0 \\
20.0 \\
20.0 \\
40.0\end{array}$ \\
\hline $\begin{array}{l}\text { Pain/ } \\
\text { Discomfort }\end{array}$ & $\begin{array}{l}\text { No problem } \\
\text { Slight problem } \\
\text { Moderate problem } \\
\text { Severe problem } \\
\text { Unable to do }\end{array}$ & $\begin{array}{l}9.1 \\
40.9 \\
45.5 \\
4.5 \\
0\end{array}$ & $\begin{array}{l}3.4 \\
13.8 \\
24.1 \\
44.8 \\
13.8\end{array}$ & $\begin{array}{l}0 \\
0 \\
40.0 \\
40.0 \\
20.0\end{array}$ \\
\hline $\begin{array}{l}\text { Anxiety/ } \\
\text { Depression }\end{array}$ & $\begin{array}{l}\text { No problem } \\
\text { Slight problem } \\
\text { Moderate problem } \\
\text { Severe problem } \\
\text { Unable to do }\end{array}$ & $\begin{array}{l}40.9 \\
18.2 \\
40.9 \\
0 \\
0\end{array}$ & $\begin{array}{l}6.9 \\
10.3 \\
31.0 \\
44.8 \\
6.9\end{array}$ & $\begin{array}{l}40.0 \\
0 \\
20.0 \\
40.0 \\
0\end{array}$ \\
\hline
\end{tabular}

Table 5 VAS Profile of DRESS, SJS and SJS/TEN Patients Based on EQ-5D-5L

\begin{tabular}{|l|l|l|l|}
\hline VAS Score & DRESS (\%) & SJS (\%) & SJS/TEN (\%) \\
\hline $\begin{array}{l}\text { The best health } \\
\text { The worst health }\end{array}$ & 9.1 & 3.4 & 0 \\
\end{tabular}

The management of DRESS, SJS, and TEN patients in acute phase included discontinuation of drugs causing skin reactions, providing support and therapy. ${ }^{26}$ In this study, fluids and electrolytes are used by all the patients. The fluid and electrolyte requirements is an essential element of SJS/TEN therapy. Therefore, appropriate fluid replacement therapy is needed in conditions of hyponatremia, hypokalemia, or hypophosphatemia. ${ }^{26}$ The previous research at Dr. Soetomo hospital, found that the improvement in the balance of electrolytes and protein in SJS and TEN patients was $100 \%$ and $88.8 \%$, respectively. ${ }^{18}$
According to this study, the most widely used therapies for SJS and TEN patients is corticosteroid, both injectable and orally administered. The systemic corticosteroids used at Sardjito general hospital are $5 \mathrm{mg} / \mathrm{mL}$ injection of dexamethasone, $125 \mathrm{mg}$ of methyl prednisolone, $16 \mathrm{mg}$ of methyl prednisolone, $8 \mathrm{mg}$ of methyl prednisolone, and $5 \mathrm{mg}$ of prednisone tablets. In the study conducted in India, all patients received systemic corticosteroids, such as dexamethasone (64.44\%), prednisolone (31.11\%), and dexamethasone and prednisolone pulse therapy $(8.88 \%) .^{24}$ The study conducted by Chantaphakul et al (2015) stated that steroid was more used for the patients that survived from SJS and TEN compared to the non-survivors, while the use of corticosteroids prevented eye complications. ${ }^{27}$

The DRESS patients have better quality of life in all domains compared to those with SJS and/or TEN. According to Zavala et al, (2018) study, patients with SJS/TEN were characterized by necrosis and extensive epidermal shedding (epidermolysis). These symptoms made SJS/TEN patients had a higher level of difficulty in carrying out their daily activities. ${ }^{28}$ The research conducted by Nishikaku et al, (2016) showed that the survivors of SJS/TEN experienced severe emotional and physical complications, as well as health-related life quality problems that required long-term medical treatment. ${ }^{29}$ Severe physical complications, which are experienced by SJS/TEN survivors may affect patients' health and lives. These complications can be not sufficiently treated by the physician due to the under recognized symptoms. ${ }^{30}$ Even though DRESS patients often find multi-organ involvement, such as liver, lung, kidney, and blood disorders, they are still able to carry out their normal activities. However, the mean VAS score and utility of normal population in Indonesia was higher than our findings. The VAS score of normal population was 79.38 (SD: 14.01) and the utility value as 0.91 (SD: 0.11). ${ }^{16}$ The SJS/TEN patients who have long-term complications might also experience psychological complications and decreased of quality of life. Thus, the psychological support during and after the hospitalization must be considered to increase their quality of life. ${ }^{31}$

The small sample size and the generic questionnaire are the study limitation for our study. Due to the importance of the finding, it is suggested to do the future studies with the bigger sample size and using the specific questionnaire for skin disease. 


\section{Conclusions}

The quality of life of DRESS patients is better than the quality of life of SJS and SJS/TEN patients. The differences of quality of life could be influenced by the symptoms of the disease.

\section{Acknowledgments}

Director of Sardjito Hospital, Yogyakarta for the permission of this study.

\section{Disclosure}

The authors have no conflicts of interest in this work.

\section{References}

1. Indonesia Ministry of Health. Keputusan Menteri Kesehatan RI No. 676/Menkes/SK/V/2005 Tentang Pedoman Umum Pengadaan Obat Program Kesehatan Tahun 2005 (Guideline of Procurement of Health Program Drugs). Jakarta: Kementrian Kesehatan Republik Indonesia; 2005.

2. Badan POM RI. Drug Safety for Patient Safety. Badan POM RI Bulletin Berita MESO. 2016;34(1):1-7.

3. Vanini A, Hutomo M. Manifestasi klinis sindroma DRESS (Drug Reaction with Eosinophilia and Systemic Symptom) (clinical manifestation of DRESS (Drug Reaction with Eosinophilia and Systemic Symptom) syndrome. Berkala Ilmu Kesehatan Kulit Dan Kelamin. 2010;22(1):40-44.

4. Borges SM, Caballero-Fonseca F, Capriles-Hulett A, Aveledo GL. Hypersensitivity reactions to nonsteroidal anti-inflammatory drugs an update. Pharmaceuticals. 2010;3(1):10-18. doi:10.3390/ph3010010

5. Mehrholz D, Emilia A, Hers M. A retrospective study of DRESS drug reaction with eosinophilia and systemic symptoms. Psychiatr Pol. 2017;51(6):1079-1093. doi:10.12740/PP/74358

6. Lin YF, Yang CH, Sindy H, et al. Severe cutaneous adverse reactions related to systemic antibiotics. Clin Infect Dis. 2014;58 (10):1377-1385. doi:10.1093/cid/ciu126

7. De A, Rajagopalan M, Sarda A, Das S, Biswas P. Drug reaction with eosinophilia and systemic symptoms: an update and review of recent literature. Indian J Dermatol. 2018;63(1):30-40. doi:10.4103/ijd. IJD_582_17

8. Musette $\mathrm{P}$, Janela B. New insights into drug reaction with eosinophilia and systemic symptoms pathophysiology. Front Med. 2017;4:179. doi:10.3389/fmed.2017.00179

9. Hsu DY, Brieva J, Silverberg NB, Silverberg JI. Morbidity and mortality of Stevens Johnson syndrome and toxic epidermal necrolysis in United States adults. J Invest Dermatol. 2016;136 (7):1387-1397. doi:10.1016/j.jid.2016.03.023

10. Putri ND, Mutiara H, Hasudungan H, Siberio HT, Sukohar A. Steven Johnson syndrome et causa paracetamol. J Medula UNILA. 2016;6 (1):101-107.

11. Abdulah R, Suwandiman TF, Handayani N, Destiani DP, Suwantika AA. Incidence, causative drugs, and economic consequences of drug-induced SJS, TEN, and SJS-TEN overlap and potential drug drug interactions during treatment: a retrospective analysis at an Indonesian referral hospital. Ther Clin Risk Manag. 2017;13:919-925. doi:10.2147/TCRM.S142226

12. Thong BYH. Stevens-Johnson syndrome/toxic epidermal necrolysis: an Asia-Pacific perspective. Asia Pac Allergy. 2013;3(4):215. doi:10.5415/apallergy.2013.3.4.215
13. Yang MS, Kim JY, Kang MG, et al. Direct costs of severe cutaneous adverse reactions in a tertiary hospital in Korea. Korean $J$ Intern Med. 2017;34(1):195-201. doi:10.3904/kjim.2015.365

14. James J, Sammour YM, Virata AR, Nordin TA, Dumic I. Drug reaction with eosinophilia and systemic symptoms (DRESS) syndrome secondary to furosemide: case report and review of literature. Am J Case Rep. 2018;19:163-170. doi:10.12659/ AJCR.907464

15. Nogueira R, Franca M, Lobato MG, Belfort R, Souza CB, Gomes JÁP. Qualidade de vida dos pacientes portadores de síndrome de Stevens-Johnson. Arq Bras Oftalmol. 2003;66 (1):67-70. doi:10.1590/S0004-27492003000100013

16. Purba FD, Hunfeld JAM, Iskandarsyah A, et al. The Indonesian EQ-5D-5L Value Set. Pharmaco Economics. 2017;35 (11):1153-1165. doi:10.1007/s40273-017-0538-9

17. Velasco-Tirado V, Alonso-Sardon M, Cosano-quero A, et al. Life threatening dermatoses: Stevens Johnson syndrome and toxic epidermal necrolysis, impact on the Spanish public health system (2010-2015). PLoS One. 2018;13(6):1-12. doi:10.1371/journal.pone.0 198582

18. Rahmawati YW, Indramaya DM. Studi retrospektif: sindrom Stevens Johnson dan epidermal toksik (retrospective study: Stevens Johnson syndrome and toxic epidermal). Berkala Ilmu Kesehatan Kulit Dan Kelamin. 2018;28(2):68-76.

19. Stella M, Clemente A, Bollero D, Risso D, Dalmasso P. Toxic epidermal necrolysis (TEN) and Stevens-Johnson syndrome (SJS): experience with high-dose intravenous immunoglobulins and topical conservative approach. Burns. 2007;33(4):452-459. doi:10.1016/j. burns.2006.08.014

20. Wang L, Mei XL. Drug reaction with eosinophilia and systemic symptoms: retrospective analysis of 104 cases over one decade. Chin Med J. 2017;130(8):943-949. doi:10.4103/0366-6999.204104

21. Anna RW, Zhou L, Li Y, Phadke NA, Chow A, Kimberly GB. Drug Reaction with Eosinophilia and Systemic Symptoms (DRESS) syndrome identified in the electronic health record allergy module. $J$ Allergy Clin Immunol. 2019;7(2):633-640. doi:10.1016/j. jaip.2018.08.013

22. Kardaun SH, Jonkman MF. Dexamethasone pulse therapy for Stevens-Johnson syndrome/toxic epidermal necrolysis. Act Derm Venereol. 2007;87(2):144-148. doi:10.2340/00015555-0214

23. Roongpisuthipong W, Sirikarn P, Theerawut K. Retrospective analysis of corticosteroid treatment in Stevens Johnson syndrome and/or toxic epidermal necrolysis over a period of 10 Years in Vajira Hospital, Navamindradhiraj University, Bangkok. Dermatol Res Pract. 2014;2014:1-5. doi:10.1155/2014/237821

24. Lihite RJ, Mangala L, Ajoy B, Debeeka H, Sukhjinder S. A study on drug induced Stevens Johnson Syndrome (SJS), Toxic Epidermal Necrolysis (TEN) and SJS-TEN overlap in a tertiary care hospital of Northeast India. J Young Pharm. 2016;8(2):149-153. doi:10.5530/ jyp.2016.2.18

25. Saka B, Akakpo AS, Teclessou JN, et al. Ocular and mucocutaneous sequelae among survivors of Stevens-Johnson syndrome and toxic epidermal necrolysis in togo. Dermatol Res Pract. 2019;2019:30. doi:10.1155/2019/4917024

26. Creamer D, Walsh SA, Dziewulski P, et al. UK guidelines for the management of Stevens-Johnson syndrome/toxic epidermal necrolysis in adults 2016. J Plast Reconstr Aesthet Surg. 2016;69 (6):736-741. doi:10.1016/j.bjps.2016.04.018

27. Chantaphakul H, Sanon T, Klaewsongkram J. Clinical characteristics and treatment outcome of Stevens Johnson syndrome and toxic epidermal necrolysis. Exp Ther Med. 2015;10:519-524. doi:10.3892/etm.2015.2549

28. Zavala S, O'Mahony M, Joyce C, Baldea AJ. How Does SCORTEN Score. J Burn Care Res. 2018;39(4):555-561. doi:10.1093/jbcr/ irx016 
29. Nishikaku AS, Gompertz OF, Disciplina DDI. Major emotional and physical complications among survivors of Stevens-Johnson syndrome and toxic epidermal necrolysis. $J$ Am Acad Dermatol. 2016;74(5):AB61.

30. Olteanu C, Shear NH, Chew HF, et al. Severe physical complications among survivors of Stevens-Johnson syndrome and toxic epidermal necrolysis. Drug Saf. 2018;41(3):277-284. doi:10.1007/s40264-0170608-0
31. Dodiuk-Gad RP, Olteanu C, Feinstein A, et al. Major psychological complications and decreased health-related quality of life among survivors of Stevens-Johnson syndrome and toxic epidermal necrolysis. Br J Dermatol. 2016;175(2):422-424. doi:10.1111/ bjd.14799

\section{Publish your work in this journal}

Patient Preference and Adherence is an international, peer-reviewed, open access journal that focusing on the growing importance of patient preference and adherence throughout the therapeutic continuum. Patient satisfaction, acceptability, quality of life, compliance, persistence and their role in developing new therapeutic modalities and compounds to optimize clinical outcomes for existing disease states are major areas of interest for the journal. This journal has been accepted for indexing on PubMed Central. The manuscript management system is completely online and includes a very quick and fair peer-review system, which is all easy to use. Visit http:// www.dovepress.com/testimonials.php to read real quotes from published authors. 